\title{
Defluoridation of water by activated carbon prepared from banana (Musa paradisiaca) peel and coffee (Coffea arabica) husk
}

\author{
T. Getachew $\cdot$ A. Hussen • V. M. Rao
}

Received: 16 February 2013/Revised: 5 February 2014/ Accepted: 12 March 2014/Published online: 9 April 2014

(C) Islamic Azad University (IAU) 2014

\begin{abstract}
The defluoridation of ground water is regarded as one of the key areas of attention among the universal water community. The present investigation deals with fluoride removal from aqueous solution by thermally activated biosorbents prepared from banana (Musa paradisiaca) peel and coffee (Coffea arabica) husk. Fluoride ion selective electrode was used for the determination and monitoring of fluoride ion concentration. Batch experiments were conducted to establish the optimal conditions like $\mathrm{pH}$, dose of the adsorbent, and contact time. The optimum $\mathrm{pH}$ was found to be 2 for both the adsorbents, and the optimum dose was found to be $24 \mathrm{~g} /$ $250 \mathrm{~mL}$ at $13 \mathrm{~h}$ contact time for banana peel and $18 \mathrm{~g} / 250 \mathrm{~mL}$ at $3 \mathrm{~h}$ contact time for coffee husk. The concentrations determined in real water samples of flour factory, poultry, and Lake Hawassa sites were 12.54, 11.02, and $6.72 \mathrm{mg} / \mathrm{L}$, respectively. The prepared biosorbents were applied on these water samples under optimized conditions and found to be effective with removal efficiency ranging from 80 to $84 \%$. In terms of time and adsorbent dose required, coffee husk was observed to be much better than banana peel. The adsorption process obeyed Langmuir adsorption model. From the kinetic perspective, the fluoride adsorption followed the pseudo second-order reaction kinetics.
\end{abstract}

Keywords Fluoride · Adsorption capacity · Adsorption isotherm · Adsorption kinetics

T. Getachew

Department of Chemistry, College of Natural and Computational Sciences, BuleHora University, P. O. Box 144, Bule Hora, Ethiopia

A. Hussen $(\bowtie) \cdot$ V. M. Rao

Department of Chemistry, School of Graduate Studies, Dilla University, P. O. Box 419, Dilla, Ethiopia

e-mail: ahmed.hussen29@yahoo.com

\section{Introduction}

Water is one of the basic needs of life on earth. It may be contaminated by natural sources or by industrial effluents. One such contaminant is fluoride. It exists in different chemical forms in combination with other elements. It is distributed widely in nature, both in inanimate and living things (Abebe 2010). Though fluoride is an essential constituent, depending on its level of fluoride in drinking water, it can be either beneficial or detrimental to human health (Alagumuthu et al. 2011). When the concentration of fluoride in drinking water is above $1.5 \mathrm{mg} / \mathrm{L}$, it results in dental, skeletal, and non-skeletal fluorosis due to its strong attraction by positively charged calcium ion in teeth and bones (Venkata Mohan et al. 2007; Shahid et al. 2008). Ethiopia is one of the 23 countries in the world, where a significant number of its population suffers from the toxic effects of high levels of fluoride in drinking water. The toxic effect of excess amount of fluoride in the drinking water of several towns in the Ethiopian Rift Valley has been in evidence since the 1970s. This was due to the fact that the people in these areas were accustomed to drinking water that contains as much as $33 \mathrm{mg} / \mathrm{L}$ (Hassen 2007). Hence, there is a need for the development of simple and cost-effective methods to remove the excess fluoride from the drinking water.

There are different methods for the removal of fluoride such as chemical treatment, membrane separation, electrolytic defluoridation, electrodialysis, membrane filtration, precipitation, nanofiltration, coagulation, electrocoagulation, chemical precipitation, reverse osmosis, and ion exchange. However, these techniques have certain disadvantages such as incomplete removal, complicated treatment process, high cost, high energy requirement and operational cost, use of chemicals, and generation of toxic 
sludge or other waste products that again require disposal (Dubey and Shiwani 2012; Aliabadi et al. 2012; Kumar et al. 2012). Adsorption processes using natural adsorbents or agricultural waste products are becoming the new alternatives for the removal of fluoride from aqueous solution as they are cheap, simple, sludge-free, regenerable, environment friendly, involve small initial cost, and minimal chemical use (Saka et al. 2012; Zhu et al. 2012).

In the literature, defluoridation was studied using different biosorbents such as Cynodon dactylon-based activated carbon (Alagumuthu et al. 2011), thermally activated carbon prepared from neem (Azadirachta indica) and kikar (Acacia arabica) leaves (Kumar et al. 2008), carbonaceous adsorbents such as wood charcoal or bone charcoal, coconut coir or animal bones (Sivasamy et al. 2001), metal ions impregnated activated charcoal (Janardhana et al. 2006), activated charcoal prepared from wheat husk- and alum-treated fly ash (Singh et al. 2000), bone charcoal, peels of Citrus documana, Citrus medica, and Citrus aurantifolia fruits-based activated carbon (Chakrapani et al. 2010), Moringa indica bark, chitin/cellulose composite (Jayapriya et al. 2011), chitosan-coated silica (Vijaya and Krishnaiah 2009), corn cobs (Hemant et al. 2006), rice husk (Waheed et al. 2009), tamarind seed and Moringa indica-based activated carbon (Murugan and Subramanian 2006; Karthikeyan and Ilango 2007), and bone meal (Gao et al. 2009). So far, no report was found in the literature regarding utilization of banana peel and coffee husk for defluoridation. However, these materials are available aplenty in this region. Thus, in the present work, a study of fluoride removal efficiency and adsorption capacity of banana peel and coffee husk was undertaken. This research was performed at Dilla University, Ethiopia, during the academic year 2011-2012.

\section{Materials and methods}

Equipment and apparatus

Fluoride ion was measured by fluoride ion selective electrode (JENWAY). A pH/ISE meter (JENWAY, model 3520) equipped with fluoride selective electrode was employed. The $\mathrm{pH}$ was measured with $\mathrm{pH} / \mathrm{ion}$ meter using $\mathrm{pH}$ glass electrode. The $\mathrm{pH}$ meter was calibrated by $\mathrm{pH}$ calibration buffers each time measurements were made.

\section{Reagents}

Analytical grade reagents $\mathrm{NaF}, \mathrm{NaOH}, \mathrm{HCl}, \mathrm{NaCl}$, $\mathrm{CH}_{3} \mathrm{COOH}$ (glacial), sodium citrate, EDTA, and concentrated $\mathrm{H}_{2} \mathrm{SO}_{4}$ were used throughout the experiment.
Anhydrous sodium fluoride $(0.221 \mathrm{~g})$ was weighed and transferred into $1,000-\mathrm{mL}$ volumetric flask. It was dissolved in double distilled water (fluoride free) and then diluted to $1 \mathrm{~L}$. The resultant solution containing $100 \mathrm{mg} / \mathrm{L}$ of fluoride was considered as stock fluoride solution. Lower concentrations are prepared by diluting the stock solution.

The total ionic strength adjustment buffer (TISAB) was prepared following the procedure developed by Agarwal et al. (2003). Accordingly $57 \mathrm{~mL}$ of glacial acetic acid, $58 \mathrm{~g}$ of $\mathrm{NaCl}, 7 \mathrm{~g}$ of sodium citrate, and $2 \mathrm{~g}$ of EDTA were added to $500 \mathrm{~mL}$ of double distilled water and allowed to dissolve, and then, the $\mathrm{pH}$ was adjusted to 5.3 with $6 \mathrm{M}$ $\mathrm{NaOH}$. Finally, the solution was adjusted up to $1,000 \mathrm{~mL}$ in a volumetric flask with double distilled water.

\section{Preparation of adsorbents}

Banana peel and coffee husk were collected from Gedeo zone, Ethiopia. The collected banana peels were washed with water to remove dust and other impurities and dried in the sun. About $100 \mathrm{~g}$ of crushed banana peels were kept in a muffle furnace for $1 \mathrm{~h}$ at $400{ }^{\circ} \mathrm{C}$, at which all of the materials were completely carbonized. The carbonized material was cooled, powdered, and kept in a beaker of 1,000-mL capacity, and $40 \mathrm{~mL}$ of concentrated sulfuric acid was gradually added to it by stirring the contents of the beaker continuously to ensure thorough mixing. The beaker was kept in an oven at $100{ }^{\circ} \mathrm{C}$ for $5 \mathrm{~h}$. The activated charcoal was then cooled and left overnight and then washed to remove all the acid and dried at $110{ }^{\circ} \mathrm{C}$ for $2 \mathrm{~h}$. Then, it was ground and sieved using standard sieves having a mesh size of $0.6 \mathrm{~mm}$.

The collected coffee husk was first washed with water to remove dust and other impurities and then was treated with hot distilled water and dried at $100{ }^{\circ} \mathrm{C}$. After that $100 \mathrm{~g}$ of this was treated with $50 \mathrm{~mL}$ of concentrated $\mathrm{H}_{2} \mathrm{SO}_{4}$ and carbonized at $150{ }^{\circ} \mathrm{C}$ for $12 \mathrm{~h}$. The adsorbent was dried and ground, then passed through standard sieves having a mesh size of $0.6 \mathrm{~mm}$.

\section{Method of fluoride quantification}

Five standard solutions were prepared from the stock solution in the range of $5-25 \mathrm{mg} / \mathrm{L}$ by serial dilution. Calibration graph was plotted as potential versus the logarithm of concentration of fluoride ion. The slope and intercept were used to convert the experimentally obtained potential into concentration of fluoride. The correlation coefficient for the calibration graph obtained was 0.9999, which shows excellent correlation between the concentration of the fluoride and potential obtained in the experiment. 
The liquid-phase fluoride concentration was measured by taking equal volumes $(10 \mathrm{~mL})$ of sample or standards and total ionic strength adjustment buffer (TISAB) in a 50-mL plastic beaker, and the mixture was stirred uniformly (at stirrer speed of level 3 for $1 \mathrm{~min}$ ) using magnetic stirrer. The same amount of sample was used throughout the experiment.

\section{Preliminary test}

Before conducting optimization experiment, preliminary test was carried out on adsorption performance of the adsorbents used. For this purpose, $250 \mathrm{~mL}$ of $15 \mathrm{mg} / \mathrm{L}$ of fluoride standard solution was transferred to two different 500-mL Erlenmeyer flasks into which $10 \mathrm{~g}$ of each adsorbent was added. Then, the samples were shaken at speed of $200 \mathrm{rpm}$. A filtrate of $10 \mathrm{~mL}$ was withdrawn at different times $(0.5,1,3,5,7,9,11,13,15,17$, and $24 \mathrm{~h})$, and residual fluoride concentration was determined.

\section{Adsorption study}

All batch experiments were conducted using $250 \mathrm{~mL}$ of aqueous solution containing known fluoride concentration to which a weighed amount of banana peel or coffee husk was added. This solution is then stirred continuously at room temperature to achieve equilibrium. A sample was periodically taken out from each flask and filtered through a Whatman No. 1 filter paper before fluoride analysis. All the adsorption studies were performed in triplicate, and average values were used to plot the graphs. The adsorption efficiency $(\%)$ and the defluoridation capacity $\left(\mathrm{mg} \mathrm{F}^{-}\right.$ adsorbed/g of adsorbent) at a given contact time for the selected adsorbents were determined using the Eqs. 1 and 2 (Vijaya and Krishnaiah 2009; Solangi et al. 2009).

Percentage removal $=\frac{\left[C_{o}-C_{t}\right]}{C_{o}} \times 100$

Adsorption capacity $=\frac{\left[C_{o}-C_{t}\right]}{m} \times V$

where $C_{0}$ is initial fluoride concentration, $C_{t}$ is residual fluoride concentration at time $t, m$ is mass of the adsorbent, and $V$ is volume of the solution used in the batch.

\section{Optimization of different parameters}

Optimization is carried out to make some parameters function at their best by varying one parameter while keeping other parameters constant. The effect of major parameters like adsorbent dose, contact time, $\mathrm{pH}$, and initial fluoride concentration were optimized.

\section{Effect of adsorbent dosage and contact time}

Experimental investigations were carried at different dosages of adsorbent ranging from 9 to $24 \mathrm{~g} / 250 \mathrm{~mL}$ of fluoride solution with $10 \mathrm{mg} / \mathrm{L}$ initial fluoride concentration at different contact times. The dosage range and initial fluoride concentration were selected based on the preliminary test results.

\section{Effect of $p H$}

To study the influence of solution $\mathrm{pH}$ on fluoride removal, the test solutions containing $10 \mathrm{mg} / \mathrm{L}$ of fluoride were adjusted to $\mathrm{pH}$ values of $2,3,4,5,6,7,8,9$, and 10 using $1 \mathrm{~N} \mathrm{HCl}$ and $1 \mathrm{~N} \mathrm{NaOH}$. Then, $24 \mathrm{~g}$ of pretreated banana peel was added to the test solutions separately and shaken for $13 \mathrm{~h}$. Residual fluoride ion concentration was analyzed in each experiment. In the case of the adsorbent prepared from coffee husk, the $\mathrm{pH}$ of the solution was adjusted to the same $\mathrm{pH}$ values in a similar way. Then, $18 \mathrm{~g}$ of pretreated coffee husk was added to test solution. The mixtures were shaken for $3 \mathrm{~h}$, and residual fluoride ion concentrations were analyzed.

\section{Effect of initial fluoride concentration}

To investigate the effect of initial fluoride concentration, experiments were conducted at various fluoride concentrations $(5,10,15,20 \mathrm{mg} / \mathrm{L})$ keeping adsorbent dose and contact time fixed at $24 \mathrm{~g}$ and $13 \mathrm{~h}$ and $18 \mathrm{~g}$ and $3 \mathrm{~h}$ for banana peel and coffee husk, respectively.

\section{Real water samples}

The real water samples having higher concentrations of fluoride were collected in consultation with water resource development authority office at Hawassa city, Ethiopia. Accordingly ground water samples were collected from Hawassa Flour Factory and Poultry using convenience sampling method. The surface water samples were collected from Lake Hawassa using composite sampling technique. Water samples were collected in cleaned (using deionized water) 5-L plastic bottles. The efficiency of each adsorbent was tested under optimized conditions.

\section{Experiments for adsorption isotherms}

Adsorption isotherms were determined using treated adsorbents at room temperature. Data for plotting isotherm were obtained by mixing a constant fluoride ion concentration of $25 \mathrm{mg} / \mathrm{L}$ with a series of increasing adsorbent dosages $(9,12,15,18,21$, and $24 \mathrm{~g})$. The mixture was agitated for $24 \mathrm{~h}$ to ensure the equilibrium, and residual 
Fig. 1 Residual fluoride concentration for different adsorbent doses of treated $\mathbf{a}$ banana peel and $\mathbf{b}$ coffee husk as a function of time (concentration of fluoride is $10 \mathrm{mg} / \mathrm{L}$ and $\mathrm{pH}$ is 6.32)

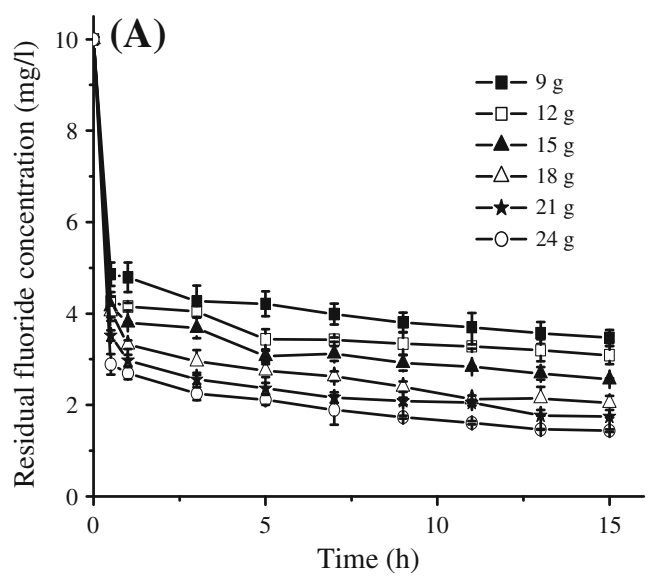

fluoride was determined after filtration. Based on the data generated, adsorption isotherms were plotted.

\section{Adsorption kinetics for fluoride removal}

Adsorption kinetics were determined using constant surface loading of 5, 10, and $20 \mathrm{~g}$ corresponding to the initial fluoride concentration of 10,20 , and $40 \mathrm{mg} / \mathrm{L}$, respectively. Residual fluoride concentrations were measured at different time intervals of $0.5,1,3,5,7,9,11,13,15,17$, and $24 \mathrm{~h}$ by taking $10 \mathrm{~mL}$ of samples periodically.

\section{Results and discussion}

\section{Preliminary test}

It is observed that different adsorbents have different adsorption efficiencies for the same initial fluoride concentration under similar conditions. In the case of adsorbent prepared from banana peel, the removal efficiency was $55 \%$ after $3 \mathrm{~h}$ of contact time. Using coffee husk, removal efficiency of $52 \%$ was observed within $0.5 \mathrm{~h}$ of contact time while banana peel showed $34 \%$ efficiency for the same duration. Therefore, from the preliminary test, one can see that both the adsorbents have a potential for adsorption of fluoride ion, but the contact times for a certain percentage removal were quiet different. Based on these, optimizations of important parameters were carried out to further improve the removal efficiency. The results of the optimization are presented in the subsequent sections.

\section{Adsorbent dose and contact time}

As can be seen in Fig. 1, the residual fluoride concentration decreases as the contact time increases for both the adsorbents. More than $50 \%$ of initial fluoride concentration was removed in the first half an hour for all the doses (9-24 g) in the case of treated banana peel (Fig. 1a). The rate of removal of fluoride becomes slow after $0.5 \mathrm{~h}$. This is because initially all the active sites were free as a result the removal efficiency was fast, and subsequently, it decreases with increasing contact time due to the saturation of the active sites. But with the increase in adsorbent dose, the rate of removal also increased because of availability of additional active sites. In order to bring the fluoride concentration into the permissible limit of $0.5-1.5 \mathrm{mg} / \mathrm{L}$ in water, a contact time of $13 \mathrm{~h}$ and a minimum dose of $24 \mathrm{~g}$ are required. This combination of contact time and adsorbent dose enables $85 \%$ of fluoride removal. In the case of coffee husk, $80 \%$ of the initial fluoride concentration was removed within half an hour with a dose of $18 \mathrm{~g}$ (Fig. 1b). The fluoride concentration became lower than the permissible level after a contact time of $3 \mathrm{~h}$. Therefore, the contact time of $3 \mathrm{~h}$ and $18 \mathrm{~g}$ of dose were taken as optimal conditions for the removal of fluoride. Similar observations were made by activated charcoal (Tembhurkar and Dongre 2006) and leaves of neem (A. indica), pipal (Ficus religiosa), and khair (Acacia catechu willd) (Jamode et al. 2004).

The response of adsorbent dose (banana peel) at a fixed fluoride concentration of $10 \mathrm{mg} / \mathrm{L}$ and contact time of $13 \mathrm{~h}$ is presented in Fig. 2. The result indicates that the removal efficiency significantly increased with dosage. The increase in fluoride adsorption efficiency was due to the large number of available fluoride binding sites resulting from the increased adsorbent dose. On the other hand, the adsorption capacity decreases with increasing dose. To maintain maximum capacity and high removal efficiency, the surface loading (i.e., the mass ratio of fluoride to adsorbent dose) should be lower than the optimum value. The surface loading for optimum fluoride removal is less than or equal to $0.1042 \mathrm{mg} / \mathrm{g}$. A dose of $24 \mathrm{~g}$ corresponding to the capacity of $0.0889 \mathrm{mg} / \mathrm{g}$ of adsorbent was considered for further adsorption studies (Fig. 2). 


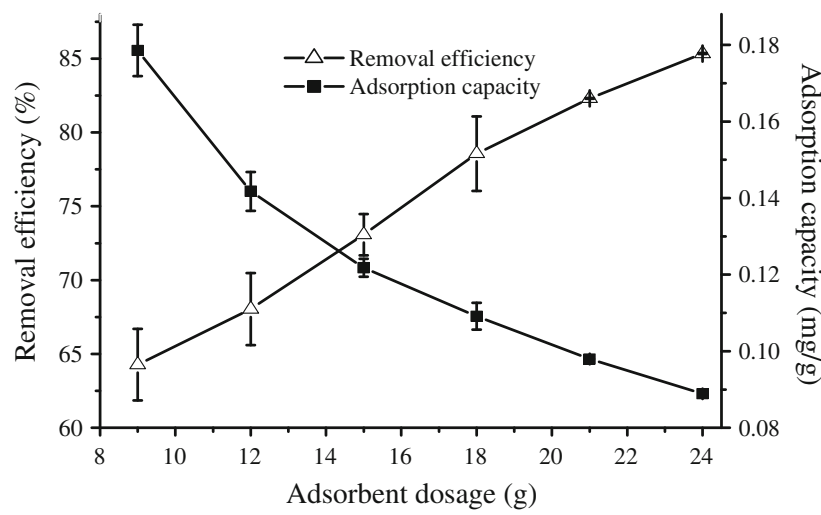

Fig. 2 Fluoride removal efficiency and adsorption capacity for the adsorbent prepared from banana peel as a function of adsorbent dose (concentration of fluoride is $10 \mathrm{mg} / \mathrm{L}, \mathrm{pH}=6.32$, and contact time is $13 \mathrm{~h})$

Thermally treated coffee husk also showed the same pattern as treated banana (Fig. 2). But, the surface loading for optimum fluoride removal was less than or equal to $0.13889 \mathrm{mg} / \mathrm{g}$. A dose of $18 \mathrm{~g}$ corresponding to the capacity of $0.1190 \mathrm{mg} / \mathrm{g}$ of adsorbent was considered for adsorption experiments on real water samples. This result is in agreement with the result obtained for the fluoride removal using manganese oxide-modified aluminum oxide hydroxide as an adsorbent (Alemu 2009).

The only difference observed between the two adsorbents was that coffee husk brings the fluoride concentration to the permissible level with in $3 \mathrm{~h}$ of contact time for a dosage of $18 \mathrm{~g}$, whereas banana peel brings the fluoride concentration to the permissible level only after $13 \mathrm{~h}$ with a dose of $24 \mathrm{~g}$. From this, it is inferred that the coffee husk acts as a better adsorbent than banana peel.

\section{Effect of $\mathrm{pH}$}

The $\mathrm{pH}$ of the medium is one of the important parameters which significantly affects the fluoride adsorption. As can be seen in Fig. 3, the removal of fluoride decreases with increasing $\mathrm{pH}$ of the solution. The same trend has been observed for both the adsorbents at their corresponding optimized conditions of adsorbent dose and contact times. In the acidic medium, the surface of the adsorbent is highly protonated, and hence, more fluoride ions can be attracted toward the surface. That is, higher fluoride sorption rate in acidic medium is attributed to strong coulombic force of attraction between positively charged surface and negatively charged fluoride ion. The repulsion between negatively charged surface (deprotonated) and fluoride ions leads to comparatively low fluoride adsorption in alkaline medium. Similar mechanism for the effect of $\mathrm{pH}$ on fluoride adsorption has been indicated in the literature (Mondal

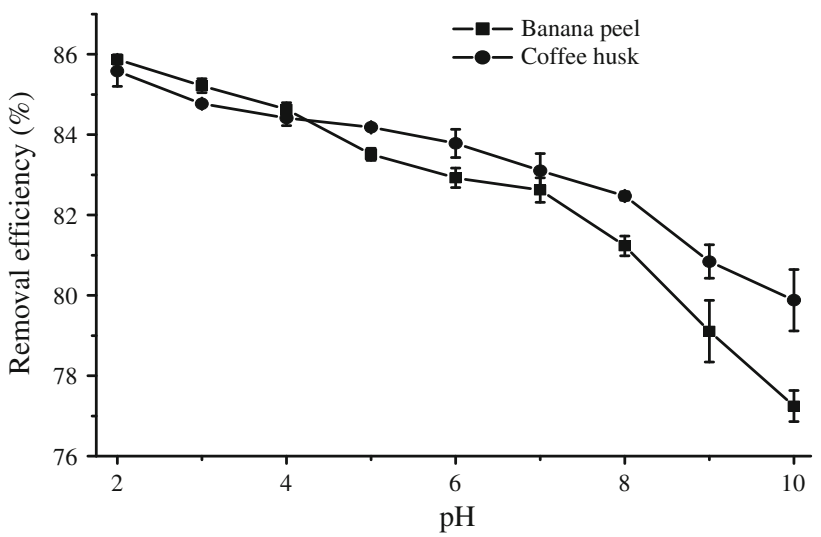

Fig. 3 Effect of pH on fluoride removal efficiency of treated banana peel (adsorbent dose $=24 \mathrm{~g}$, contact time $=13 \mathrm{~h}$ ) and coffee husk (adsorbent dose $=18 \mathrm{~g}$, contact time $=3 \mathrm{~h}$ ) with an initial fluoride concentration of $10 \mathrm{mg} / \mathrm{L}$

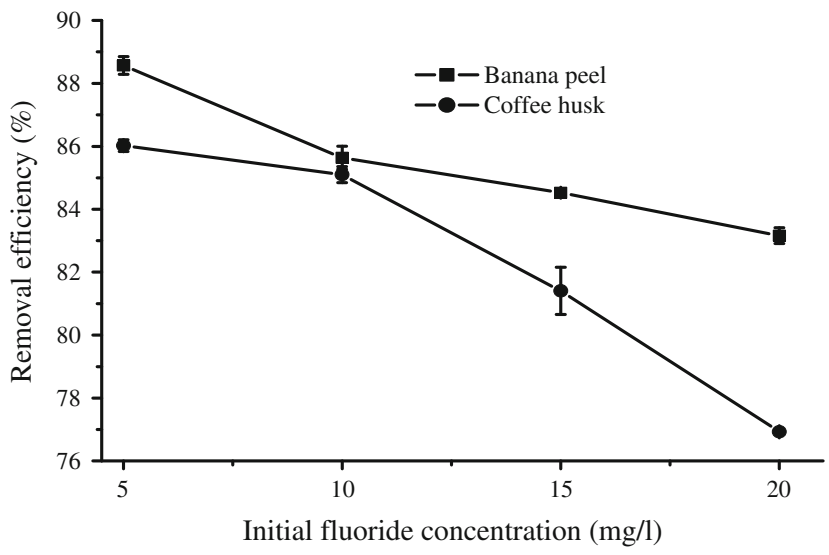

Fig. 4 Effect of initial fluoride concentration on removal efficiency of different adsorbents at optimized conditions

et al. 2012; Goswami and Purkait 2013; Chen et al. 2010b; Biswas et al. 2012). Thus, a $\mathrm{pH}$ of 2 , which gives maximum fluoride removal, was taken as an optimal $\mathrm{pH}$ for application to real water samples.

\section{Effect of initial concentration}

As shown in Fig. 4, the removal efficiency of both adsorbents decreases with increase in initial fluoride concentration. It can be observed that there is significant fluoride removal efficiency $(>85 \%)$ when the initial fluoride concentration was less than or equal to $10 \mathrm{mg} / \mathrm{L}$. Then, it declined sharply from 89 to $83 \%$ and 86 to $77 \%$, when the concentrations were increased from 5 to $20 \mathrm{mg} / \mathrm{L}$ for banana peel and coffee husk, respectively. Higher removal efficiencies at lower initial fluoride concentrations are due 
to higher ratio of active surface area to total fluoride ions, which leads to the utilization of more accessible energetically active sites on the adsorbent surface. The reason for sharp decrease of removal efficiency with the increase in initial fluoride concentration is lack of sufficient surface area to accommodate more fluoride ions available in the solution (Abdullah and Prasad 2009).

Thus, the initial fluoride concentration has an influence on sorption. Hence, it is necessary to determine initial fluoride concentration before attempting removal. The required adsorbent dosage, contact time, and $\mathrm{pH}$ to bring fluoride concentration to permissible level depend on initial fluoride concentration of the sample. If the fluoride concentration in the real water sample is high, then the dosage as well as contact time required to bring the fluoride concentration to permissible level will also be high.

\section{Application to real water samples}

Fluoride removal efficiency of the adsorbents prepared from banana peel and coffee husk has been tested on real water samples under optimized conditions for each adsorbent. The concentrations of fluoride in all the water samples collected are observed to be higher than the permissible level. The concentration of fluoride in the water sample of Lake Hawassa is $6.7155 \mathrm{mg} / \mathrm{L}$, and this concentration was reduced to 1.1678 and $1.1442 \mathrm{mg} / \mathrm{L}$ after the treatment with the adsorbents prepared from banana peel and coffee husk, respectively. The concentrations after the treatment are within the permissible limits set by WHO for drinking water. The fluoride concentrations in the ground water samples collected from Hawassa poultry and flour factory were reduced to lower concentrations but not to the permissible limits of WHO. For treating water of such high fluoride concentration, tandem defluoridation with fresh adsorbent might be effective to bring down the concentration to the safe limits. From the results presented in Table 1, it is concluded that both the adsorbents studied are having good potential to remove the fluoride present in water.
Adsorption isotherms

Freundlich and Langmuir isotherms are useful models for the description of adsorption process by different adsorbents. The Freundlich model refers to surface heterogeneity of the adsorbent, whereas the Langmuir model assumes uniform energies of adsorption onto the surface and no transmigration of the adsorbate in the plane of the surface. The Eqs. 3 and 4 are linear forms of Freundlich and Langmuir isotherm equations, respectively.

$\log q_{e}=\log K_{\mathrm{F}}+\frac{1}{n} \log C_{\mathrm{e}}$

$\frac{C_{\mathrm{e}}}{q_{e}}=\frac{1}{q_{m}} C_{\mathrm{e}}+\frac{1}{K_{a} q_{m}}$

where $q_{e}$ is the amount of fluoride ion adsorbed per unit mass of adsorbent, $\mathrm{mg} / \mathrm{g} ; C_{\mathrm{e}}$ is the equilibrium adsorbate concentration in solution, $\mathrm{mg} / \mathrm{L} ; K_{\mathrm{F}}$ and $n$ are Freundlich constants indicative of adsorption capacity $(\mathrm{mg} / \mathrm{g})$ and adsorption intensity, respectively; $q_{m}$ and $K_{a}$ are Langmuir constants representing adsorption capacity and binding strength, respectively. The adsorption intensity $(n)$ values between 1 and 10 indicate the favorable adsorption (Solangi et al. 2009).

The essential characteristics of Langmuir isotherm can be expressed in terms of a dimensionless constant, separation factor or equilibrium parameter $R_{\mathrm{L}}$ which is defined by the Eq. 5 .

$R_{\mathrm{L}}=\frac{1}{1+b C_{o}}$

where $C_{o}$ is the initial fluoride concentration, $\mathrm{mg} / \mathrm{L}$, and $b$ is the Langmuir constant, $1 / \mathrm{mg}$. The $R_{\mathrm{L}}$ value indicates the type of isotherm to be irreversible $\left(R_{\mathrm{L}}=0\right)$, favorable $\left(0<R_{\mathrm{L}}<1\right)$, linear $\left(R_{\mathrm{L}}=1\right)$, and unfavorable $\left(R_{\mathrm{L}}>1\right)$ (Chen et al. 2010a).

From the experimental, data the Freundlich constants were obtained by plotting $\log q_{e}$ versus $\log C_{\mathrm{e}}$. The calculated isotherm parameters $\left(n, K_{\mathrm{F}}\right)$ and the correlation coefficients are given in Table 2. As can be seen in the table, the values of $n$ lie between 1 and 10, indicating Freundlich favorable sorption due to increase in the bond

Table 1 Fluoride removal from the real water samples using the adsorbents prepared from banana peel and coffee husk at optimized conditions

\begin{tabular}{|c|c|c|c|c|c|}
\hline \multirow[t]{2}{*}{ Sample point } & \multirow{2}{*}{$\begin{array}{l}\text { Average concentration } \pm \mathrm{SD} \\
(n=3) \text { before treatment }(\mathrm{mg} / \mathrm{L})\end{array}$} & \multicolumn{2}{|c|}{ After treatment with banana peel (mg/L) } & \multicolumn{2}{|c|}{ After treatment with coffee husk (mg/L) } \\
\hline & & $\begin{array}{l}\text { Average } \\
\text { concentration } \\
\pm \mathrm{SD}(n=3)\end{array}$ & $\begin{array}{l}\text { Removal } \\
\text { efficiency } \\
\text { percentage }\end{array}$ & $\begin{array}{l}\text { Average } \\
\text { concentration } \\
\pm \mathrm{SD}(n=3)\end{array}$ & $\begin{array}{l}\text { Removal } \\
\text { efficiency } \\
\text { percentage }\end{array}$ \\
\hline Lake Hawassa & $6.7155 \pm 0.0262$ & $1.1678 \pm 0.0298$ & 83 & $1.1442 \pm 0.0577$ & 83 \\
\hline Hawassa poultry & $11.0212 \pm 0.0429$ & $1.9149 \pm 0.0577$ & 83 & $1.7521 \pm 0.0298$ & 84 \\
\hline Flour factory & $12.5351 \pm 0.0978$ & $2.4611 \pm 0.0273$ & 80 & $2.3824 \pm 0.0047$ & 81 \\
\hline
\end{tabular}


Table 2 Adsorption isotherm parameters and correlation coefficients

\begin{tabular}{lllllllll}
\hline Biosorbents & \multicolumn{2}{l}{ Freundlich parameters } & & \multicolumn{3}{l}{ Langmuir parameters } \\
\cline { 2 - 3 } \cline { 7 - 9 } & $n$ & $K_{\mathrm{F}}$ & $R^{2}$ & & $\begin{array}{l}q_{m} \\
(\mathrm{mg} / \mathrm{g})\end{array}$ & $\begin{array}{l}K_{a} \\
(\mathrm{~L} / \mathrm{mg})\end{array}$ & $R^{2}$ \\
\hline $\begin{array}{c}\text { Treated } \\
\text { banana peel }\end{array}$ & 3.9541 & 0.1775 & 0.9734 & 0.3950 & 0.4260 & 0.9987 \\
$\begin{array}{c}\text { Treated } \\
\text { coffee husk }\end{array}$ & 4.6019 & 0.2256 & 0.9934 & 0.4159 & 0.7895 & 0.9983 \\
\hline
\end{tabular}

energies with the increase in the surface density. Thus, it can be concluded that the sorption data manifest heterogeneity of the adsorbent surface (Jamode et al. 2004; Waheed et al. 2009; Alagumuthu et al. 2010).

Similarly, the Langmuir constants $q_{m}$ and $K_{a}$ (Table 2) were determined from the slope and intercept of linear plot of $C_{\mathrm{e}} / q_{e}$ versus $C_{\mathrm{e}}$ (Jamode et al. 2004; Chen et al. 2010a). The $R_{\mathrm{L}}$ values for the treated banana peel and coffee husk are 0.0858 and 0.0482 , respectively, which implies that the adsorption of fluoride on the adsorbents under the experimental condition is favorable. The correlation coefficient values of 0.9987 and 0.9983 for the adsorbents indicate that the data comply more to the Langmuir model than it is with Freundlich (0.9734 and 0.9934). This result is in agreement with the results obtained with powdered activated charcoal (Tembhurkar and Dongre 2006), clay (Hamdi and Srasra 2007) and A. indica (Neem) and F. Religiosa (Pipal) (Tembhurkar and Dongre 2009) as an adsorbent.

\section{Adsorption kinetics}

The kinetics analysis of the adsorption data has been done based on reaction kinetics of pseudo first-order and pseudo second-order mechanisms. The equations for pseudo first order and pseudo second order are, respectively,

$\log \left(q_{e}-q_{t}\right)=\log q_{e}-k_{1} t$

$\frac{t}{q_{t}}=\frac{1}{k_{2} q_{e}^{2}}+\frac{t}{q_{e}}$

where $q_{e}$ and $q_{t}$ are the amount of fluoride adsorbed (mg/g) at equilibrium and at any time $t ; k_{1}$ and $k_{2}$ are equilibrium rate constant of first $\left(\mathrm{min}^{-1}\right)$ and second order $\left(\mathrm{g} \mathrm{mg}^{-1} \mathrm{~min}^{-1}\right.$ ), respectively; $\mathrm{t}$ is the contact time, (h).
Fig. 5 Pseudo first-order plot for a banana peel $\mathbf{b}$ coffee husk, each with initial concentrations of $10,20,40 \mathrm{mg} / \mathrm{L}$ with the corresponding adsorbent doses of $5,10,20 \mathrm{~g}$, respectively
Fig. 6 Pseudo second-order plot for a banana peel and b coffee husk, each with initial concentration of $10,20,40 \mathrm{mg} /$ $\mathrm{L}$ with the corresponding adsorbent doses of 5, 10, $20 \mathrm{~g}$, respectively
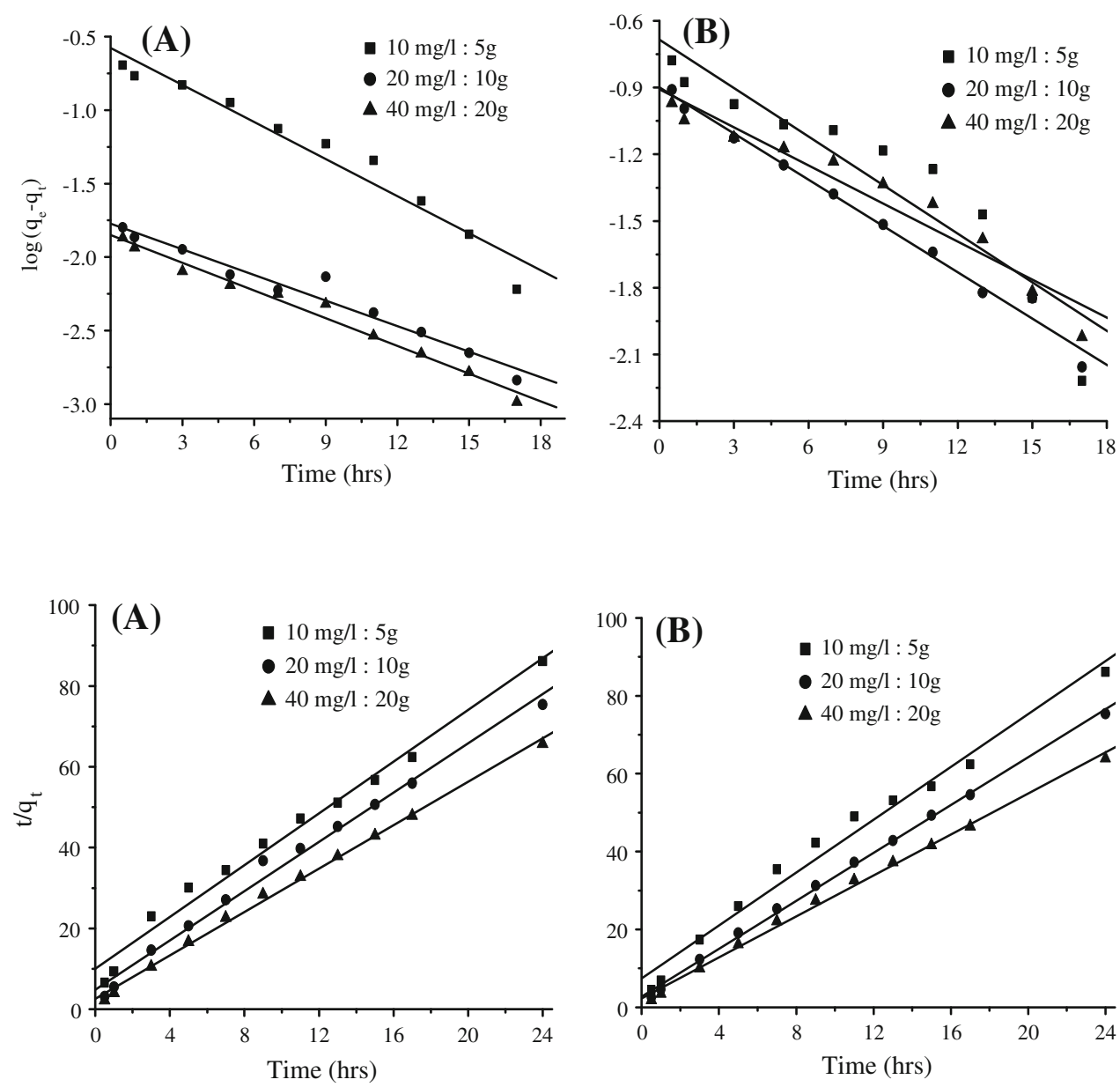
The rate constants $k_{1}$ and $k_{2}$ are calculated according to the linear plots of $\log \left(q_{e}-q_{t}\right)$ versus $t$ (Fig. 5) and $t / q_{t}$ against $t$ (Fig. 6), respectively. A larger adsorption rate constant $k_{1}$ usually represents a quicker adsorption rate. Larger the $k_{2}$ values slower the rate of adsorption. The correlation coefficients for the plot of pseudo first order are less than those of pseudo second-order reaction (Tables 3, 4). This indicates that kinetic data for adsorption of fluoride by the adsorbent prepared from banana peel and coffee husk are better fitted to pseudo second-order rate equation than to pseudo first-order rate equation. The values of pseudo first-order rate constant $\left(k_{1}\right)$ for each adsorbent are not close to each other compared to those of pseudo second-order rate constant $\left(k_{2}\right)$. Moreover, the rate constants for the three initial fluoride concentration of each adsorbent are closer to each other in the case of pseudo second-order reaction. Therefore, it is concluded that the adsorption of fluoride by these adsorbents follows the pseudo secondorder reaction kinetics. This result is in agreement with the results obtained for the defluoridation using chitosancoated silica (Vijaya and Krishnaiah 2009), clay (Hassen 2007), nanoscale aluminum oxide hydroxide (Adeno 2010) and peels of $C$. documana, C. medica, and C. aurantifolia fruits-based activated carbon (Chakrapani et al. 2010) as an adsorbent.

\section{Comparison with other adsorbents}

In order to investigate the kinetics process such as the mechanism of adsorption and potential rate controlling steps, basically the order of process has to be studied. Like most of the adsorbents studied previously such as activated silica gel and rice husk ash (Mondal et al. 2012), Schwertmannite (Goswami and Purkait 2013) and synthetic hydrous aluminum oxide (Biswas et al. 2012), the banana peel and coffee husk studied in the present work also obeyed Langmuir adsorption isotherm with pseudo secondorder kinetics. Thus, fluoride adsorption followed chemisorptions rather than physical adsorption with uniform monolayer coverage without transmigration of the adsorbate $\left(\mathrm{F}^{-}\right)$(Tor et al. 2009).

Direct comparison of the performance of these adsorbents with other adsorbent materials might be difficult, owing to the different experimental conditions under which they were applied. Nevertheless, the performance can at least be compared based on their maximum adsorption capacity $\left(q_{e}\right)$. The $q_{e}$ values depend on the initial concentration of the fluoride ions. There is a tendency of increment in $q_{e}$ as initial concentration increases. The observed $q_{e}$ for banana peel and coffee husk, at initial concentration of $10 \mathrm{mg} / \mathrm{L}$ of fluoride was 0.3123 and $0.2946 \mathrm{mg} / \mathrm{g}$, respectively. This is comparable to the $q_{e}$ value of activated rice husk ash $(0.426 \mathrm{mg} / \mathrm{g})$ and activated silica gel
Table 3 Pseudo first-order rate constants with their rate equations and correlation coefficients

\begin{tabular}{|c|c|c|c|}
\hline $\begin{array}{l}\text { Initial fluoride } \\
\text { concentration }(\mathrm{mg} / \mathrm{L})\end{array}$ & $\begin{array}{l}k_{1} \\
\left(\min ^{-1}\right)\end{array}$ & Rate equation & $R^{2}$ \\
\hline \multicolumn{4}{|c|}{ Adsorbent prepared from banana peel } \\
\hline 10 & 0.084 & $\begin{array}{l}\log \left(q_{e}-q_{t}\right)= \\
\quad-0.084 t-0.575\end{array}$ & 0.953 \\
\hline 20 & 0.058 & $\begin{array}{l}\log \left(q_{e}-q_{t}\right)= \\
\quad-0.058 t-1.772\end{array}$ & 0.962 \\
\hline 40 & 0.062 & $\begin{array}{l}\log \left(q_{e}-q_{t}\right)= \\
\quad-0.062 t-1.85\end{array}$ & 0.983 \\
\hline Average values & 0.068 & $\begin{array}{l}\log \left(q_{e}-q_{t}\right)= \\
\quad-0.068 t-1.399\end{array}$ & 0.966 \\
\hline \multicolumn{4}{|c|}{ Adsorbent prepared from coffee husk } \\
\hline 10 & 0.072 & $\begin{array}{l}\log \left(q_{e}-q_{t}\right)= \\
\quad-0.072 t-0.683\end{array}$ & 0.878 \\
\hline 20 & 0.069 & $\begin{array}{l}\log \left(q_{e}-q_{t}\right)= \\
\quad-0.069 t-0.898\end{array}$ & 0.988 \\
\hline 40 & 0.057 & $\begin{array}{l}\log \left(q_{e}-q_{t}\right)= \\
\quad-0.057 t-0.907\end{array}$ & 0.939 \\
\hline Average values & 0.066 & $\begin{array}{l}\log \left(q_{e}-q_{t}\right)= \\
\quad-0.066 t-0.829\end{array}$ & 0.935 \\
\hline
\end{tabular}

Table 4 Pseudo second-order rate constants with their rate equations and correlation coefficients

\begin{tabular}{llll}
\hline $\begin{array}{l}\text { Initial fluoride } \\
\text { concentration } \\
(\mathrm{mg} / \mathrm{L})\end{array}$ & $\begin{array}{l}k_{2} \\
\left(\mathrm{~g} \mathrm{mg}^{-1} \mathrm{~min}^{-1}\right)\end{array}$ & Rate equation & $R^{2}$ \\
\hline
\end{tabular}

Adsorbent prepared from banana peel

$\begin{array}{llll}10 & 3.202 & t / q_{t}=3.202 t+10.02 & 0.984 \\ 20 & 3.048 & t / q_{t}=3.048 t+4.829 & 0.990 \\ 40 & 2.687 & t / q_{t}=2.687 t+2.535 & 0.997 \\ \text { Average values } & 2.979 & t / q_{t}=2.979 t+5.794 & 0.990\end{array}$

Adsorbent prepared from coffee husk

\begin{tabular}{llll}
10 & 3.394 & $t / q_{t}=3.394 t+7.437$ & 0.981 \\
20 & 3.075 & $t / q_{t}=3.075 t+2.739$ & 0.998 \\
40 & 2.629 & $t / q_{t}=2.629 t+2.307$ & 0.996 \\
Average values & 3.032 & $t / q_{t}=3.032 t+4.161$ & 0.991 \\
\hline
\end{tabular}

$(0.308 \mathrm{mg} / \mathrm{g})$ at initial concentration of $15 \mathrm{mg} / \mathrm{L}$ of fluoride (Mondal et al. 2012).

\section{Conclusion}

The present study shows that thermally treated adsorbents prepared from coffee husk and banana peel are suitable for the removal of fluoride ions. The operational parameters such as adsorbent dose, contact time, $\mathrm{pH}$, and initial fluoride concentration were found to have an effect on the adsorption efficiency. At the optimum operation 
conditions, the adsorbents prepared from banana peel and coffee husk exhibited highest fluoride removal efficiency of 85 and $86 \%$, respectively, for $10 \mathrm{mg} / \mathrm{L}$ of initial fluoride concentration. Application to the real water sample also resulted in removal efficiency ranging from 80 to $84 \%$. In terms of time and adsorbent dose required, coffee husk was observed to be much effective than banana peel. The process of adsorption follows Langmuir adsorption isotherm and pseudo second-order rate equation in both cases.

Acknowledgments The authors acknowledge Ministry of Education, Dilla University, and Arba Minch University for providing instrumentation and laboratory facilities. Professor B. Seetharami Reddy and Mr. C. Ramesh Naidu are acknowledged for proof reading and drawing graphs with error bars, respectively.

\section{References}

Abdullah MA, Prasad AGD (2009) Kinetic and equilibrium studies for the biosorption of $\mathrm{Cr}(\mathrm{VI})$ from aqueous solutions by potato peel waste. Int J Chem Eng Res 1(2):51-62

Abebe W (2010) Health hazards of fluoride as related to Ethiopia: a review of some relevant issues for preventive approaches. Ethiop E-J Res Innov Foresight 2(1):59-84

Adeno F (2010) Adsorptive removal of fluoride from water using nano scale aluminium oxide hydroxide. M. Sc. Thesis. Addis Ababa University, Ethiopia

Agarwal M, Rai K, Shrivastav R, Dass S (2003) Defluoridation of water using amended clay. J Clean Prod 11:439-444

Alagumuthu G, Veeraputhiran V, Venkataraman R (2010) Adsorption isotherms on fluoride removal: batch techniques. Arch Appl Sci Res 2(4):170-185

Alagumuthu G, Veeraputhiran V, Venkataraman R (2011) Fluoride sorption using Cynodon dactylon-based activated carbon. Hem Ind 65(1):23-35

Alemu S (2009) Investigation of fluoride adsorption on manganese oxide modified aluminium oxide hydroxide. M. Sc. Thesis, Addis Ababa University, Ethiopia

Aliabadi M, Khazaei I, Fakhraee H, Mousavian MTH (2012) Hexavalent chromium removal from aqueous solutions by using low-cost biological wastes: equilibrium and kinetic studies. Int $\mathrm{J}$ Environ Sci Technol 9:319-326

Biswas K, Halder I, Dutta J, Basu T, Ghosh UC (2012) Some physicochemical aspects on fluoride adsorption from aqueous solution by synthetic hydrous aluminium oxide. Int $\mathrm{J}$ Univ Pharm Life Sci 2(4):42-65

Chakrapani CH, Suresh Babu CH, Vani KNK, Somasekhara Rao K (2010) Adsorption kinetics for the removal of fluoride from aqueous solution by activated carbon adsorbents derived from the peels of selected citrus fruits. E-J Chem 7(S1):S419-S427

Chen N, Zhang Z, Feng C, Li M, Zhu D, Chen R, Sugiura N (2010a) An excellent fluoride sorption behavior of ceramic adsorbent. J Hazard Mater 183:460-465

Chen N, Zhang Z, Feng C, Li M, Zhu D, Chen R, Sugiura N (2010b) Removal of fluoride from aqueous solution by adsorption onto Kanuma mud. Water Sci Technol 62(8):1888-1897

Dubey A, Shiwani S (2012) Adsorption of lead using a new green material obtained from Portulaca plant. Int $\mathrm{J}$ Environ Sci Technol 9:15-20
Gao S, Cui J, Wei Z (2009) Study on the fluoride adsorption of various apatite materials in aqueous solution. J Fluor Chem 130:1035-1041

Goswami A, Purkait MK (2013) Defluoridation of water by Schwertmannite. World Acad Sci Eng Technol 73:1156-1161

Hamdi N, Srasra E (2007) Removal of fluoride from acidic wastewater by clay mineral: effect of solid-liquid ratios. Desalination 206:238-244

Hassen A (2007) Selection of clay adsorbents and determination of the optimum condition for defluoridation of ground water in Rift valley region. M. Sc. Thesis, Addis Ababa University, Ethiopia

Hemant SP, Jignesh BP, Sudhakar P, Koshy VJ (2006) Removal of fluoride from water with powdered corn cobs. J Environ Sci Eng 48(2):135-138

Jamode AV, Sapkal VS, Jamode VS (2004) Defluoridation of water using inexpensive adsorbents. J Indian Inst Sci 84:163-171

Janardhana C, Nageswara Rao G, Sai Satish R, Sai Lakshman V (2006) Study on defluoridation of drinking water by impregnation of metal ions in activated charcoal. Indian J Chem Technol 13:414-416

Jayapriya G, Ramya R, Rathinam XR, Sudha PN (2011) Equilibrium and kinetic studies of fluoride adsorption by chitin/cellulose composite. Arch Appl Sci Res 3(3):415-423

Karthikeyan G, Ilango SS (2007) Fluoride sorption using Moringa indica-based activated carbon. Iran J Environ Health Sci Eng 4(1):21-28

Kumar S, Gupta A, Yadav JP (2008) Removal of fluoride by thermally activated carbon prepared from neem (Azadirachta indica) and kikar (Acacia arabica) leaves. J Environ Biol 29(2):227-232

Kumar R, Jain SK, Misra RK, Kachchwaha M, Khatri PK (2012) Aqueous heavy metals removal by adsorption on $\beta$-diketonefunctionalized styrene-divinylbenzene copolymeric resin. Int $\mathbf{J}$ Environ Sci Technol 9:79-84

Mondal NK, Bhaumik R, Banerjee A, Datta JK, Baur T (2012) A comparative study on the batch performance of fluoride adsorption by activated silica gel and activated rice husk ash. Int J Environ Sci 2(3):1643-1661

Murugan M, Subramanian E (2006) Studies on defluoridation of water by tamarind seed, an unconventional biosorbent. J Water Health 04(4):453-461

Saka C, Sahin O, Küçük MM (2012) Applications on agricultural and forest waste adsorbents for the removal of lead (II) from contaminated waters. Int J Environ Sci Technol 9:379-394

Shahid M, Bhandari DK, Ahmed I, Singh AP, Raha P (2008) Study on fluoride content of ground water in Jind district, Haryana, India. Am-Eurasian J Agric Environ Sci 4(6):670-676

Singh RP, Singh Y, Swaroop D (2000) Defluoridation of ground water in Agra city using low cost adsorbents. Bull Environ Contam Toxicol 65:120-125

Sivasamy A, Singh KP, Mohan D, Maruthamuthu M (2001) Studies on defluoridation of water by coal-based sorbents. J Chem Technol Biotechnol 76:717-722

Solangi IB, Memon Shahabuddin, Bhanger MI (2009) Removal of fluoride from aqueous environment by modified Amberlite resin. J Hazard Mater 171(1-3):815-819

Tembhurkar AR, Dongre SR (2006) Studies on fluoride removal using adsorption process. J Environ Sci Eng 48(3):151-156

Tembhurkar AR, Dongre SR (2009) Comparative studies on fluoride removal using natural adsorbents viz Azadirachta indica (Neem) and Ficus religiosa (Pipal). IE(I) J-EN 90:18-23

Tor A, Danaoglu N, Arslan G, Cengeloglu Y (2009) Removal of fluoride from water by using granular red mud: batch and column studies. J Hazard Mater 164:271-278

Venkata Mohan S, Ramanaiah SV, Rajkumar B, Sarma PN (2007) Biosorption of fluoride from aqueous phase onto algal Spirogyra 
IO1 and evaluation of adsorption kinetics. Bioresour Tech 98(5):1006-1011

Vijaya Y, Krishnaiah A (2009) Sorptive response profile of chitosan coated silica in the defluoridation of aqueous solution. E-J Chem 6(3):713-724

Waheed SD, Attar SJ, Waghmare MD (2009) Investigation on sorption of fluoride in water using rice husk as an adsorbent. Nat Environ Pollut Tech 8(2):217-223
Zhu Y, Zhang H, Zeng H, Liang M, Lu R (2012) Adsorption of chromium (VI) from aqueous solution by the iron(III)-impregnated sorbent prepared from sugarcane bagasse. Int J Environ Sci Technol 9:463-472 